\title{
Josué Montello leitor de Stendhal: relações intertextuais entre 0 vermelho e o negro e Os tambores de São Luís
}

\section{Josué Montello reader of Stendhal: intertextual relations between 0 Vermelho e o Negro and Os tambores de São Luís}

\author{
Mauro Cezar Borges Vieira* \\ vieiramaurocezar@gmail.com \\ Universidade Federal do Maranhão \\ José Dino Costa Cavalcante** \\ dinoufma@gmail.com \\ Universidade Federal do Maranhão
}

\begin{abstract}
RESUMO: Este trabalho tem como objetivo analisar as relações intertextuais existentes entre a obra $O$ vermelho e o negro, de Stendhal, e Os tambores de São Luís, de Josué Montello. Com o foco no papel da biblioteca do escritor no processo de criação literária, esperamos reconstruir um caminho de leitura que aproxime o Montello leitor de Stendhal do Montello escritor. Para isso, nos utilizamos das discussões acerca da intertextualidade em Samoyault (2008) e da biblioteca do escritor em Lopez (2007), além do aparato crítico de Montello (1973) e Oliveira (2007) e da marginália recolhida na biblioteca de Josué Montello em Stendhal (1939). Como procedimentos metodológicos, após perpassar as questões teóricas sobre a intertextualidade na biblioteca do escritor, iremos comparar escritos críticos de Montello sobre as duas obras com ênfase no tratamento dos eventos históricos que as compõem, além de analisarmos os exemplares da obra de Stendhal que figuram na biblioteca de Josué Montello. Como resultado, foram encontrados diversos pontos de convergência entre aspectos das obras que evidenciaram a influência de uma na outra, deixando claro que o processo de criação literária se utiliza de diversas técnicas para concretizar seu resultado final.
\end{abstract}

Palavras-chave: Josué Montello, Stendhal, intertextualidade, biblioteca do escritor

\footnotetext{
* Mestrando do Programa de Pós-Graduação em Letras da Universidade Federal do Maranhão (PGLetras/UFMA) na linha de pesquisa Estudos Teóricos e Críticos em Literatura, sob a orientação do Prof. Dr. Dino Cavalcant.

** Possui graduação em Letras pela Universidade Federal do Maranhão (1995), mestrado na Universidade Estadual Paulista "Júlio de Mesquita Filho" (2000) e doutorado pela Universidade Estadual Paulista "Júlio de Mesquita Filho" (2005). Atualmente é Professor Associado do Departamento de Letras da Universidade Federal do Maranhão - UFMA. Tem experiência na área de Estudos Literários, com ênfase em Literatura Brasileira. Desenvolve pesquisas nas áreas de História da Literatura, Literatura e Sociedade e Literatura Maranhense. É membro permanente do corpo docente do Mestrado em Letras da UFMA. Sua linha de pesquisa é Literatura, História e Sociedade.
} 
ABSTRACT: This work aims to analyze the intertextual relations between the work $O$ Vermelho e o Negro, by Stendhal, and Os tambourines de São Luís, by Josué Montello. With the focus on the role of the writer's library in the process of literary creation, we hope to reconstruct a way of reading that brings the Montello reader of Stendhal closer to the Montello writer. For this, we used the discussions about intertextuality in Samoyault (2008) and the writer's library in Lopez (2007), in addition to the critical apparatus of Montello (1973) and Oliveira (2007) and the marginalia collected in the library of Josué Montello in Stendhal (1939). As methodological procedures, after going through the theoretical questions about intertextuality in the writer's library, we will compare Montello's critical writings on the two works with an emphasis on the treatment of historical events that comprise them, in addition to analyzing the examples of Stendhal's work that appear in the Josué Montello's library. As a result, several points of convergence were found between aspects of the works that showed the influence of one on the other, making it clear that the process of literary creation uses different techniques to achieve its final result.

Keyword: Josué Montello, Stendhal, intertextuality, writer's library

\section{Introdução}

Josué Montello aprendeu a língua francesa quando era aluno do Liceu Maranhense. A partir daí a sua relação com a literatura francesa se intensificou, de forma que, já no ápice de sua carreira literária, o autor receberia críticas positivas dos jornais franceses a pretexto do seu livro-ensaio sobre Abbé de Saint-Réal.

Stendhal, Balzac, Zola, Saint-Real, os irmãos Goncourt, Jules Renard e diversos outros autores franceses fizeram parte de sua formação enquanto escritor. Em razão disso, não é surpresa a identificação de pontos de convergência entre sua magnum opus, Os tambores de São Luís e O vermelho e o negro, de Stendhal. Contando histórias de protagonistas que buscam ascensão social tendo como principal trunfo para subir na hierarquia da Igreja Católica a sua excelente memória, essas duas obras parecem compartilhar, além dessa, outras características em comum tais como: o fato de terem eventos reais na sua urdidura, a preocupação de seus autores serem fiéis ao tempo histórico retratado e o papel de duas mulheres na vida de cada um dos personagens principais.

Sendo assim, pode-se afirmar que as ideias de $O$ vermelho e o negro influenciaram Josué Montello na composição de sua obra sobre a escravidão? Acreditamos que sim. Passando pelas questões acerca da intertextualidade e da biblioteca do escritor, explorando os escritos diarísticos de Montello, bem como seus 
textos críticos sobre a obra de Stendhal e sobre a sua própria, buscaremos reestabelecer esse caminho percorrido pelo autor maranhense há mais de cinquenta anos.

\section{1 intertextualidade na biblioteca do escritor}

Toda escritura é resumo de leitura, jogo com possíveis livrescos, elucubração na biblioteca. (SAMOYAULT, 2008, p. 87)

Ao nos depararmos com duas obras literárias que se aproximam, quer seja pelo estilo, quer seja pelo conteúdo, de forma que se possa estabelecer relações concretas entre si, uma pergunta totalizante não demora a vir à tona: de que maneira a literatura se relaciona com ela mesma? Para além de uma análise abstrata sobre esse tópico, há que se levar em consideração o papel que a literatura exerce na formação de escritores, isto é, a relevância da biblioteca para a formação do escritor.

Partindo de um lugar mais abrangente, vamos encontrar em Samoyault (2008, p. 47) o seguinte ponto de vista acerca do papel da intertextualidade na literatura:

A literatura se escreve com a lembrança daquilo que é, daquilo que foi. Ela a exprime, movimentando sua memória e a inscrevendo nos textos por meio de um certo número de procedimentos de retomadas, de lembranças e de re-escrituras, cujo trabalho faz aparecer o intertexto. Ela mostra assim sua capacidade de se constituir em suma ou em biblioteca e de sugerir o imaginário que ela própria tem de si. Fazendo da intertextualidade a memória da literatura, propõe-se uma poética inseparável de uma hermenêutica: trata-se de ver e de compreender do que ela procede, sem separar esse aspecto das modalidades concretas de sua inscrição.

Assim, ao encarar a memória da literatura como um fator preponderante na criação literária, o autor propõe a noção de uma intertextualidade apoiada nesse dispositivo. Ou seja, há, na poética, um movimento natural que faz com que a literatura se volte para si, encarando-se num espelho do que é, do que foi e do que pode vir a ser e dessa forma se (re)invente. Nessa noção, "a intertextualidade é o resultado técnico, objetivo, do trabalho constante, sutil e, às vezes, aleatório, da memória da escritura" (SAMOYAULT, 2008, p. 68). 
Esse caminho, nos leva a um questionamento da noção de originalidade que já não pode ser mais posta em pé nos termos comuns num universo de múltiplos caminhos intertextuais. Perde-se a noção de ideia original e, por outro lado, abre-se um escopo para se pensar num plano de originalidade de usos das ideias, como afirma Samoyault (2008, p. 70):

Não há oposição que valha, para a literatura, entre o inédito e o já-dito. Se o roubo de idéia (sic) é um crime dificil de se estabelecer, é justamente porque a criação se exerce não na matéria, mas na maneira ou no encontro de uma matéria e de uma maneira.

E Samoyault (2008, p. 71) ainda completa: "As idéias (sic) não pertencem a ninguém, elas circulam, voam, dispersam-se e pousam, de acordo com os ventos, cuja orientação é preciso medir". Portanto, se utilizar de ideias já usadas para compor enredos, personagens, situações e diálogos abre espaço para se discutir as relações entre leitura e escrita. Vale ressaltar que essa circulação de influência sempre foi bem recepcionada quando se trata de estilos e técnicas narrativas. Um dos pontos de aglutinação das escolas literárias é, justamente, sua aproximação estilística. Contudo, ao se tratar de circulação de ideias, o espaço sempre foi reduzido ao plano de obras que estavam debaixo do mesmo movimento literário, como afirma Moisés (2013) com relação à tendência que tinham os escritores realistas de atribuir defeitos morais a seus personagens ou, como afirma o autor "mostrar o mal sem Ihe dar remédio" (MOISÉS, 2013, p. 231). A discussão que se pretende aqui funda-se na tese de que a circulação de ideias acontece dentro da biblioteca do escritor - para além dos limites das chamadas "escolas literárias" - operando um jogo de influências que pode ser alcançado pelo crítico tanto no estilo quanto no conteúdo, pois acredita-se que "as atividades de leitura e de escritura se interpenetram então como em reflexos sem fim". (SAMOYAULT, 2008, p. 78).

É importante demarcar o espaço em que se pretende colocar essa discussão. Samoyault (2008), em seu estudo sobre a intertextualidade, aponta diversos mecanismos pelos quais pode-se perceber a circulação de textos sobre outros, numa experiência que nos leva a considerar a intertextualidade como fator inerente à literatura. Entre paródias e pastiches, a autora cobre um espaço de discussão que vai do propósito do autor à recepção do leitor passando pelas diversas características que o dispositivo intertextual pode ter. Em relação a esse útlimo ponto, uma primeira 
divisão pode ser feita entre o que se poderia encarar como intertextualidade expressa e intertextualidade não-expressa. A primeira se daria de forma direta, através de citação, epígrafe ou qualquer outra forma que remeta diretamente ao texto de origem, ao passo que a segunda se 'esconde' no texto, só podendo ser retomada pelo compartilhamento da mesma biblioteca entre escritor e leitor. Sobre isso, Samoyault (2008, p. 85) afirma:

Os jogos com a biblioteca nem sempre desmembram o corpo dos textos, assim como também não nivelam as referências da memória histórica. Ocorre com freqüência (sic) que os escritores se servem de seu saber para inscrever nos textos uma homenagem disfarçada $[\ldots]$.

Dessa maneira, podemos concluir que, no caso dessa intertextualidade que não deixa marcas, não se pode apontar, ou deixar de apontar, intencionalidade no processo de criação, afinal, não há nada no texto que nos levaria a afirmar uma coisa ou outra. Assim, pode-se questionar: como podemos considerar que houve influência de um texto em outro? Nesse universo de intertextualidade não-expressa, como atestar a própria existência de intertextualidade? Samoyault (2008, p. 68) resolve essa questão afirmando que "a dificuldade do levantamento constitui o reverso da extensão prática: um texto esconderia quase sempre um outro, disporia sempre de um subtexto, mesmo quando nada autoriza seu desvelamento".

Nesse aspecto, cabe ressaltar que o próprio Josué Montello reconhece textualmente essa influência dos escritores lidos na pena daqueles que estão escrevendo. Na crônica Conversa para leitores de Stendhal, o autor maranhense esclarece que:

Cada um de nós, à medida que vai formando seu espírito, no mundo das letras, contrai dívidas de reconhecimento para com os autores que nos foram úteis nessa formação. E a tendência é pagarmos em louvores esparsos esses débitos da juventude. Ou então saldar de uma vez a dívida antiga com a unidade de um ensaio ou de um estudo. (MONTELLO, 2009, p. 303)

Ainda na crônica em questão, Montello relata conversas que ele teve com outros leitores de Stendhal enquanto morava em Paris. A presença de um excerto como o acima, que dialoga com as proposições de Samoyault (2008) já descritas nesse trabalho, num texto montelliano em que o principal personagem é o próprio 
Stendhal marca uma confissão, mesmo que velada, do fato de que o maranhense encara o pseudônimo de Henri Beyle como um de seus mestres.

Não bastasse isso, há outros dois fatores que corroboram para esse entendimento. O primeiro deles são as menções que Montello faz a Stendhal em seus diários. De 1952 - data de início de seus escritos diarísticos - até 1975 - data da publicação de Os tambores de São Luís - são 38 excertos que fazem menção à Stendhal distribuídos em três publicações, a saber: Diário da manhã, Diário da tarde e Diário do entardecer. Em relação a isso, Lopez (2007, p. 33, grifo nosso) ao se debruçar sobre o tema da biblioteca do escritor afirma que "cartas, crônicas, diários e depoimentos desses leitores diferenciados beneficiam sobremodo o estudo de todos os aspectos aludidos".

O segundo fator que corrobora para a tese de que Montello tem em Stendhal, e, por conseguinte, em $O$ vermelho e o negro, um modelo de literatura, reside na presença dessa obra na biblioteca pessoal do autor, conservada na Casa de Cultura Josué Montello. Afora a extensa coleção stendhaliana, a obra em questão é encontrada em três edições no acervo pessoal do escritor, sendo uma delas depositária de vestígios da leitura montelliana em forma de destaques e notas. Esses vestígios, também conhecidos como marginalia, são evidências da importância de determinada passagem, quer seja por seu estilo ou por seu conteúdo, para o leitor Montello e, consequentemente, para o escritor Montello como nos afirma Lopez (2007, p. 33): "[...] as notas marginais que selecionam trechos e palavras, ao recolher, no texto alheio, idéias (sic), concepções, achados de estilo, informações, personagens etc concretizam, nas obras freqüentadas (sic), um celeiro da criação". Ainda evidenciando a importância da biblioteca do escritor para a investigação dos momentos de criação, a autora completa dizendo que:

As bibliotecas de escritores têm se mostrado de capital interesse para a compreensão dos caminhos tomados por poetas, ficcionistas, críticos ou jornalistas. Como somatório de títulos, contribuem para a história da leitura; como espaço da criação, ligam-se implícita ou explicitamente à gênese de obras, ao nos propor matrizes e, na marginália, materializar instantes da escritura. (LOPEZ, 2007, p. 33)

Montello era um defensor da ideia de que a leitura influenciava a escrita de maneira propositiva, tanto que defende essa ideia na passagem a seguir do seu 
ensaio Confissões de um romancista, onde o autor maranhense analisa a biblioteca de Guimarães Rosa:

Nunca me esqueço de que, na noite em que morreu Guimarães Rosa, tendo sido o primeiro amigo a chegar ao seu apartamento, andei a repassar-lhe os livros, na pequena biblioteca que o cercava, e ali vi, já curioso da posteridade que para ele começava, os volumes que tinham sido objeto de suas leituras mais atentas. Apanhei ao acaso um volume de Aquilino Ribeiro. Estava todo anotado. Outro mais. Também pontilhado de reparos. Era a prova de que Rosa não se limitara a ler o mestre português do Malhadinhas - estudara-lhe o estilo, palavra a palavra, meticulosamente, como o mestre de Dom Casmurro estudara certos clássicos portugueses, não para imitá-los, mas para aprender com eles. (MONTELLO, 1986, p. 33)

É assim que chegamos no ponto em que leitura e escrita se relacionam numa intertextualidade produtora, que serve a criação literária, proporcionando a existência do já mencionado espaço da memória da literatura. A título de encerramento desse ponto, cabe acrescentar à essa discussão o resumo que Lopez faz dessa relação intertextual que se estabelece entre a criação literária e a biblioteca do escritor:

Nas influências reconhecidas, nas leituras declaradas, na presença de determinadas obras na biblioteca de um escritor, nas notas autógrafas à margem de leituras ou em folhas apensas e em todas as formas e feições do trabalho nesse espaço, insinuam-se matrizes, instaurando o diálogo que traz a intertextualidade da criação. (LOPEZ, 2007, p. 33)

É sob esse escopo teórico que nos debruçamos na análise das relações existentes entre O vermelho e o negro, de Stendhal e Os tambores de São Luís, de Josué Montello, com vistas a estabelecer paralelos que evidenciem o papel intertextual da biblioteca do escritor no processo criativo da magnum opus do maranhense. Para isso, nos utilizaremos de excertos diarísticos, registros documentais de leitura, o aparato crítico construído pelo próprio Josué Montello sobre O vermelho e o negro e sobre a sua obra, além, é claro, da comparação entre elementos das obras.

\section{Aproximações entre Os tambores de São Luís e $O$ vermelho e o negro}


A angústia da influência, que sente todo criador, leva-o a se servir do que leu, a tomar modelos para em seguida deformá-los. (SAMOYAULT, 2008, p. 129)

Se em relação ao estilo e técnicas narrativas não se pode estabelecer uma relação tão próxima entre Os tambores de São Luís e O vermelho e o negro, no que se refere a características de enredo, as similaridades são muito fortes. Apesar de terem motivações diferentes, Damião e Julien Sorel, respectivos protagonistas romanescos, traçam um percurso de ascensão social através da igreja. Os dois alimentam o desejo não só de se tornarem padres mas de galgar os caminhos de ascenção na hierarquia da igreja de Roma e tem, como seu principal trunfo, uma memória invejável que Ihes possibilita um aprendizado rápido. Contudo, ambos sofrem com sua passagem pelo seminário, notadamente um lugar que não olha para os seus méritos, somente para a sua posição de origem naquelas sociedades desiguais. Utilizando-se do prestígio que é ter estudado na escola de formação de padres, Julien e Damião, embora falhem no objetivo de serem ordenados, conseguem ocupar posições sociais minimamente importantes. Como se não bastasse esse percurso semelhante, ambos os personagens tem seus caminhos cruzados por duas mulheres em fases diferentes de suas vidas e que terão papel primordial nas suas jornadas.

As relações entre Montello e Stendhal são facilmente identificáveis do decorrer dos seus diários. Sendo um ávido leitor de literatura francesa, o maranhense tem no pseudônimo de Henri Beyle um dos seus escritores preferidos. Contudo, a relação entre as leituras stendhalianas e sua produção romanesca começa a se tornar patentes antes mesmo do início do processo de composição de Os tambores de São Luís. Quando, em 1957, Montello, em Lisboa, decide começar a escrever o seu quarto romance, que se chamaria $A$ décima noite, o autor usa Stendhal, e seu processo de criação de A Cartuxa de Parma, para compor a entrada do dia 4 de março daquele ano, afirmando que recolheu o ensinamento do mestre francês e se utilizou dele para construir o argumento da narrativa que será escrita:

Em carta a Balzac, confessou Stendhal que, ao escrever La Chartreuse de Parme, lia, todas as manhãs, 'pour prende le ton', duas ou três páginas do Código Civil. 
Mas há outra razão, não apontada por Stendhal, para que um romancista leia o mesmo código, e também o Código Penal. Cada artigo, em qualquer um deles, é um romance a desenvolver, visto que foi a lembrança de um caso concreto, recolhido à vida real, que certamente o inspirou.

Há dois anos, no Rio, abrindo ao acaso o nosso Código Civil, eu disse à minha mulher:

- Eis aqui um bom tema de romance.

E li para ela o parágrafo IV do artigo 219 , sobre a anulação do casamento por erro essencial de pessoa.

Ela, após ouvir-me com atenção:

- Por que não escreves esse romance?

E eu, decidindo-me:

Vai chamar-se A décima noite.

Assim nasceu o romance que, há dois dias, comecei a escrever aqui em Lisboa, nesta pequena sala de meu apartamento na avenida Fontes Pereira de Melo. Sinto a pena fluir, puxando o longo fio do novelo romanesco. Situei-o em São Luís, motivado pelo ambiente de sobrados de azulejos que me cerca. $E$ vou sentindo que os personagens ganham forma e movimento, à medida que as páginas vão se acumulando, na urdidura da narrativa. (MONTELLO, 1998, p. 419-420)

Assim, quando o autor maranhense resolve encontrar soluções para o enredo de Os tambores de São Luís que se assemelham, no que se refere ao seu protagonista, com o já descrito em $O$ vermelho e o negro, todo o escopo teórico descrito no primeiro item desta análise se movimenta para dar conta da influência deste livro naquele autor e, especificamente, naquela que, junto com Cais da Sagração, é considerada sua magnum opus. Um caminho que, como notado, Montello já tinha começado a percorrer.

\subsection{Relações entre as obras}

No ensaio A saga romanesca de Josué Montello, o crítico Franklin de Oliveira, ao analisar as obras do autor maranhense publicadas até 1985, levanta a seguinte questão quando se volta para Os tambores de São Luís:

Montello está mais próximo de uma tradição da novela como uma terceira dimensão da História [...] a de Stendhal, que em Le rouge et le noir registra a época abjeta da Restauração [...] (OLIVEIRA, 2017, p. 35-36, grifo nosso)

Josué Montello, no texto crítico intitulado O vermelho e o negro - de Stendhal, publicado em 1973 pela revista Manchete, dá especial atenção a esse caráter 
histórico, reconhecendo, no subtítulo da primeira edição do livro, sua vocação historiográfica:

Por baixo do título do romance, Stendhal havia posto esta indicação, significativa de seu propósito: crônica de 1830. Quer isso dizer que, além da verdade psicológica, relacionada aos seres humanos que compunham a narrativa, tinha em mente o romancista fazer de seu livro um quadro de costumes sociais e políticos. (MONTELLO, 1973, p. 103, grifo do autor)

Essa postura em relação à história, que pode ser resumida pela epígrafe escolhida por Stendhal para o capítulo XIII do livro 1 de O vermelho e o negro - a saber, "Um romance é um espelho que carregamos ao longo de um caminho" (SAINTRÉAL apud STENDHAL, 2016, p. 84) - parece ter sido incorporada pelo próprio Montello na composição de Os tambores de São Luís. Oliveira (2017, p. 36) reconhece isso ao aproximar a epígrafe de Saint-Réal às escolhas narrativas da história de Damião:

Uma das matrizes do romance histórico está no Abbé de Saint-Réal [1639-1692], mestre de Stendhal, e com quem Montello se identifica tão profundamente [...] que chegou a lhe dedicar um livro escrito e publicado em Paris, elogiado pelas maiores autoridades em Henri Beyle, o genial desbravador de muitos caminhos da ficção moderna. Não só aquela aliança entre o romanesco e a historiografia que há em Os tambores de São Luís parece apontar para o maître oublié de Stendhal. A definição de Saint-Réal de romance como 'um espelho que se leva ao longo de um caminho' ajusta-se à novelística montelliana.

É importante notar que Montello dedica todo um estudo sobre Saint-Réal, publicado na França em 1970 sob o título Un maître oublié de Stendhal, motivado por essa epígrafe, o que também viria a aproximar o maranhense de Henri Martineau, um dos maiores conhecedores da obra de Stendhal. É nesse espírito, que Montello (1986, p. 56) afirma, em Confissões de um romancista: "conscientemente, portanto, dei a Os Tambores de São Luís a configuração da narrativa histórica, nos dois arcos que a compõem - procurando conciliar o espírito plástico e o espírito crítico, no processo da criação romanesca".

Porém, a forma como os autores encaram a história na composição de seus romances não é o único ponto de aproximação entre ambos. No que se refere à composição de personagens, Montello parece ter se servido de um dos artifícios 
revelados por Stendhal em suas cartas à Balzac: a transposição de figuras da vida real para o romance. Cabe deixar claro que esse processo não consistia numa simples cópia das características físicas e de personalidade, mais do que isso, Stendhal parece ressignificar seus personagens "reais" ao transportá-los para a página em branco, como podemos perceber nos excertos a seguir:

Eu tomo um personagem que conheço bem, deixo-lhe os hábitos que ele contraiu na arte de ir todos os dias em busca da felicidade, em seguida the dou um pouco mais de espírito. (STENDHAL apud MONTELLO, 1973, p. 103)

Descrevendo um homem, uma mulher, tenha sempre em mente alguma coisa de real. (STENDHAL apud MONTELLO, 1973, p. 103)

Além de dar a Julien muitas de suas características e de seus comportamentos pessoais, Stendhal punha em cena tipos e figuras que trazia na memória, como reminiscências bem vividas. (MONTELLO, 1973, p. 103)

Esse suporte da realidade, como instrumento de elaboração do romance, é que dá nitidez às figuras de $\mathbf{O}$ Vermelho e o Negro. Não estamos diante de simples comparsas de um drama, mas sim de seres humanos, retirados da vida real para o livro, e em cujo espelho de paixões e sentimentos vemos refletidos os nossos sentimentos e paixões. (MONTELLO, 1973, p. 103, grifo do autor)

Essa é uma das técnicas de composição de personagens que Josué Montello, tacitamente, revela em páginas do seu diário e, mais especificamente, no prefácio de Cais da Sagração, intitulado Antes do Romance (MONTELLO, 2017). Ao tratar dos seus próprios personagens em Os tambores de São Luís, Montello tergiversa sobre a transposição de figuras reais para o romance mas acaba reconhecendo esse uso:

Nunca transferi da vida real para o texto literário, intencionalmente, as figuras e os dramas de meus romances ou de minhas novelas. Se a vida real constitui, em alguns casos, o ponto de partida, ou a sugestão inicial, minha imaginação se encarregou de transfigurála, com os recursos que tirou de si mesma. (MONTELLO, 1986, p. 35 , grifo nosso)

Apesar de propalar essa falta de intenção na transposição de figuras, um dos casos de Os tambores de São Luís parece corroborar para uma afirmativa diametralmente oposta a essa. É o caso do pai de Montello, que é personagem da narrativa. Aparecendo em somente uma cena, o senhor Antônio Montello, que tinha 
uma loja de sapatos ${ }^{1}$, se encontra com Damião, no caminho que o negro faz até a Camboa para visitar seu trineto que acaba de nascer:

E foi mais perto, já no círculo de luz do lampião, que identificou, na figura forte, de rosto vermelho, o seu amigo Antônio Montello, a quem devia a velha conta de um par de botinas.

- Olá! - exclamou.

E depois de acender o cigarro, que ficou segurando com a ponta dos dedos enquanto chupava a primeira fumaça:

- Por que esse violino? - quis saber.

- Uma vez por semana, para desenferrujar os dedos, vou tocar na orquestra do Pedro Cromwell, depois que fecho a loja.

- Quer dizer que, além de comerciante, é músico?

- Nas horas vagas.

- E protestante também?

- Com a graça de Deus - confirmou o outro, descobrindo-se. (MONTELLO, 2019, p. 254-255)

Talvez a mais importante relação que se possa estabelecer entre os dois romances reside no fato de se relacionarem, na sua gênese, com fatos verídicos. $O$ crime final de Julien, que, dentro de uma igreja, tenta assassinar a sra. de Rênal ao descobrir que o antigo relacionamento dos dois tinha sido revelado ao seu sogro, o sr. de La Mole, foi o fato real que Stendhal descreve em O vermelho e o negro, como nos conta Montello (1973, p. 102, grifo do autor):

No caso de $\mathbf{O}$ Vermelho e o Negro foi a própria vida que lhe forneceu a substância do romance, com o caso judiciário narrado pela Gazette des Tribunaux, nos seus números de 28 a 31 de dezembro de 1827. Tratava-se de um crime passional cometido por Anthoine Berthet, que tentara matar Madame Michoud numa igreja depois ensaiara suicidarse, tendo sido condenado à morte pelo tribunal de Grenoble.

As consequências reais do crime também foram transpostas para o romance, como se pode perceber. A sra. de Renal sobrevive, assim como Madame Michoud, e, após um tempo na prisão onde ensaia um suicídio, tanto Julien Sorel quanto Anthoine Berthet são condenados a morte.

\footnotetext{
${ }^{1}$ Cf. Montello, 1986. No ensaio Confissões de um romancista, Montello abre o panorama de sua obra escrita contando cenas de sua juventude. Numa delas, Montello reconhece que, ao ajudar o pai, sendo balconista da loja, não se interessava muito pelo ofício e passava as tardes lendo. Vale ainda ressaltar que, além de desejar que Josué lhe sucedesse na loja de sapatos, o sr. Antônio Montello queria Ihe fazer Pastor da Igreja Presbiteriana, como ele próprio.
} 
Recheado por figuras e acontecimentos reais, há um deles que se sobressai em relação aos outros no enredo de Os tambores de São Luís, não só pela precisão histórica como também pela importância narrativa. Trata-se do crime da baronesa de Grajaú. Ana Rosa Viana Ribeiro, casada com Carlos Ribeiro, vice-presidente da província que, anos depois receberia o título de barão de Grajaú, foi acusada de assassinar dois negros durante uma sessão de tortura na sua casa, situada na Rua de São João. Num Maranhão escravagista, anos antes da abolição, a certeza da impunidade pairava sobre toda a província. Contudo, o promotor Celso Magalhães apresenta uma denúncia de homicídio contra aquela que era uma das mais altas damas da sociedade maranhense. Depois de ter sido julgada inocente, o promotor consegue não só levar o caso para a segunda instância, no Tribunal de Apelação, como também manter a baronesa encarcerada até a data do novo julgamento. No Tribunal do Júri, a ré é inocentada por unanimidade. Meses depois, ao assumir interinamente a presidência da província, Carlos Ribeiro exonera Celso Magalhães do cargo que ocupava. O agora ex-promotor morre, meses depois.

No romance montelliano, Damião é a pessoa que provoca o promotor Celso Magalhães para que ele possa tomar uma providência. Além disso, é ele o encarregado de levar notas à imprensa para dar atestação à sociedade do andamento do caso, bem como cabe a Damião a tarefa de recolher o estado de espírito nas ruas e informá-lo ao promotor. Neres (2015, p. 21) ao comparar o desfecho do caso no romance montelliano e nos autos do processo afirma que "o resultado do julgamento é fidedigno ao que consta nos autos processuais [...]". A despeito de um sentimento de fracasso que the acomete, Damião resolve, a partir de então, se engajar na luta abolicionista de vez, decisão que ele passou boa parte da narrativa protelando. É a partir desse caso que ele volta a ganhar notoriedade na sociedade maranhense e, consequentemente, usa isso em favor de sua causa antiescravagista. Sousa (2018, p. 146, grifo nosso) compartilha dessa visão ao afirmar que "a narrativa apresenta o caso de Dona Ana Rosa Ribeiro nos tribunais, momento em que a personagem Damião definitivamente torna-se ativista da causa negra".

O próprio Montello intencionou colocar este caso, emblemático da luta dos negros contra o fim dos sofrimentos que lhe eram impostos, como parte importante do seu romance. No seu Diário do entardecer e no posfácio de Os tambores de São Luís ele conta como obteve os autos do processo pelas mãos do então senador José 
Sarney. Reproduzimos aqui o trecho de História deste romance, publicado como posfácio da obra de Os tambores de São Luís:

Eu havia pensado em incluir no livro, como um de seus episódios capitais, o famoso crime da baronesa de Grajaú. De tanta repercussão na sociedade maranhense do tempo do Império. Onde encontrar o seu relato? $\mathrm{E}$ eis que um dia, de passagem por Brasília, nas minhas andanças de reitor, fui almoçar na casa do senador José Sarney. Conversa vai, conversa vem, e entre o tinido dos talheres e a mudança dos pratos, falei-lhe do crime, para ver se ele poderia ajudar-me a recompô-lo. Sarney saiu da mesa e voltou daí a momentos com dois volumes compactos de papéis velhos, que passou às minhas mãos:

- Aí tem você o processo da baronesa. É seu." (MONTELLO, 2019, p. 733-734)

Não bastasse essa intenção clara de recolher as impressões deste evento histórico, Montello ainda teve a coincidência de, atuando como reitor da Universidade Federal do Maranhão, ter o seu gabinete situado no Solar do barão de Grajaú, como ele conta a seguir:

Volvidos alguns dias, estava eu no meu gabinete da Reitoria, às voltas com problemas universitários, quando franzi a testa, olhando à minha volta, no gabinete vazio. Levantei-me, andei pelo casarão, estendi o olhar por seu pátio e por suas escadas: naquele sobrado morara a baronesa de Grajaú, e fora ali, precisamente ali, que ela praticara o seu crime! (MONTELLO, 2019, p. 734)

Assim, como escrevia Os tambores de São Luís, durante intervalos de suas obrigações no avião, na sala de espera do então Ministro da Educação Jarbas Passarinho e no seu próprio gabinete, Montello teve a oportunidade de narrar o crime da baronesa no mesmo local em que ele havia acontecido.

Essa proximidade em relação a dois eventos que aconteceram e foram transpostos para as páginas em branco de seus respectivos romances, amarra mais um laço na teia de relações que se pretende estabelecer entre $O$ vermelho e o negro e Os tambores de São Luís. Talvez um último nó tenha que ser dado no ponto em que essa relação é mais factual, ou seja, nos seus protagonistas e, para isso, vamos adentrar a biblioteca pessoal de Montello, conservada na Casa de Cultura que leva seu nome.

\subsection{Le rouge et le noir na biblioteca montelliana}


$\mathrm{Na}$ biblioteca montelliana, foram encontradas três edições de $\mathrm{O}$ vermelho e o negro, todas elas editadas na França. Uma delas reúne as cartas que são mandadas entre os personagens do romance, de forma que não constitui o romance em sua totalidade. Das outras duas edições, chama a atenção a editada pela Librairie Garnier Frères, em 1939, pois é nesta que encontramos os vestígios da leitura de Josué Montello. Essa edição conta ainda com notas, cronologia, introdução, bibliografia, além de outros paratextos, todos eles de autoria de Henri Martineau.

Vale lembrar que, ao se buscar vestígios da leitura de Josué Montello, buscase restabelecer o caminho da criação literária do escritor em sua biblioteca, afinal "[...] as notas marginais que selecionam trechos e palavras, ao recolher, no texto alheio, idéias (sic), concepções, achados de estilo, informações, personagens etc concretizam, nas obras freqüentadas (sic), um celeiro da criação". (LOPEZ, 2007, p. 33). E Lopez (2007, p. 33, grifo nosso) ainda conclui dizendo que:

As matrizes são principais quando se ligam ao modo de formar; quando textos ou elementos de um texto - temas, motivos, seqüências (sic), cenas, personagens, estilo, tratamento do tempo e do espaço etc - enraízam a (re)criação que se afirma com originalidade e autonomia ao integrar outro contexto. Desse ponto de vista, as matrizes, consolidadas ou não pela marginália de um escritor, descobertas no circuito de um diálogo intertextual, interessam também à literatura comparada. Matrizes e marginalia nos conduzem, por força da intertextualidade e da dimensão documentária, à tentativa de reconstituir, no diálogo, certas instâncias do ato criador enquanto conjunção de leitura e escritura, convergência na esfera intelectual.

Os trechos marcados por Montello em sua leitura somam-se 24, entre excertos do próprio texto romanesco, da cronologia da história e das notas de Henri Martineau. Em consonância com o espírito deste trabalho estão àqueles que fazem referência à memória de Julien, artifício que o personagem se utiliza como trunfo em sua ascensão social, como os trechos a seguir:

Avec une âme de feu, Julien avait une de ces mémoires étonnantes si solvente unies à la soutise. Pour gagner le vieux curé Chélan, duquel il voyant bien que dépendait son sort à venor, il avait appris par coeur tout le Nouveau Testament em latin; il savait aussi le livre du Pape de 
M. de Maistre et croyant à l'um aussi peu qu'á l'autre" (STENDHAL, 1939 , p. 20, grifo do autor) ${ }^{2}$

[...] et on le vit constamment, dans la scie de son père, occupé à apprendre par coeur une bible latine que le curé lui avait prêtée (STENDHAL, 1939, p. 23) 3

Também Damião, por motivos diferentes, faz uso das leituras em latim de textos religiosos para se estabelecer como boa figura frente aos homens da igreja, como pode ser observado neste trecho:

Já agora não somente podia repetir, sem um erro, corridamente, o latim da missa, como lhe conhecia o sentido e a significação. Havia terminado a Arte Latina, do Padre Figueiredo, que em parte sabia de cor. Aos poucos, orientado pelo Padre Policarpo, ia lendo um livro atrás de outro, até tarde, à fraca luz do velho candeeiro. (MONTELLO, 2019, p. 226)

Isso demonstra como os caminhos de Julien Sorel e Damião parecem se assemelhar, quer seja nos acontecimentos da vida, quer seja nos métodos adotados para se chegar ao objetivo final.

Mais à frente, nas notas, organizadas por $\mathrm{H}$. Martineau, Montello marca o seguinte trecho "29. Stendhal va insister bientôt sur l'étonnante mémoire de Julien Sorel. Mais lui-même, dans Henri Brulard, nous confesse qu'il avait appris par coeur em entier le Nouveau Testament en latin" (MARTINEAU, 1939, p. 543) ${ }^{4}$. Ocorre que, em Confissões de um romancista, o próprio Montello confessa também ter memorizado capítulos inteiros de livros da Bíblia:

A mim me tocou ler a Bíblia para toda a família, assim que meu pai descobriu no filho o gosto da leitura. Hoje, se ainda sei de cor capítulos inteiros do Velho e Novo testamento, devo-o a esses serões de infância e juventude. (MONTELLO, 1986, p. 15, grifo nosso)

\footnotetext{
2 "Com uma alma fogos, Julien possuía uma dessas memórias espantosas, tão frequentemente unidas à tolice. Para conquistar o velho cura Chélan, de quem sabia depender sua sorte futura, aprendera de cor todo o Novo testamento em latim; sabia também o livro Do papa, do sr. de Maistre, e acreditava tão pouco num quanto no outro". (STENDHAL, 2016, p. 26, tradução livre)

3 "[...] e passaram a vê-lo constantemente, na serraria do pai, empenhado em decorar uma bíblia latina emprestada pelo cura". (STENDHAL, 2016, p. 30, tradução livre)

4 "29. Stendhal logo se demorará na memória surpreendente de Julien Sorel. Mas ele mesmo, em Henri Brulard, nos confessa que memorizou o Novo Testamento em latim" (MARTINEAU, 1939, p. 543, tradução livre).
} 
Por fim, Montello marca uma das passagens na qual Julien presencia uma reunião em que se discute política. Ele está incumbido de fazer um relatório dessa reunião, memorizá-lo e transmiti-lo a um interlocutor na Inglaterra. No meio do capítulo, Stendhal faz uma parada na narração para colocar o seguinte:

- Si vos personnages ne parlent pas politique, reprend l'éditeur, ce ne sont plpus des Français de 1830, et votre livre n'est plus um miroir, comme vous em avez la prétention... (STENDHAL, 1939, p. 376) ${ }^{5}$.

Essa lição parece ter sido recolhida por Montello. Enquanto trata dos assuntos acerca de Os tambores de São Luís no ensaio Confissões de um romancista, o autor assevera que:

A esta altura, cumpre acentuar que, de certo modo, todo romance é histórico, visto que se subordina, não apenas à natureza, mas igualmente a um contexto social, cultural ou político, claramente delimitado pelo tempo transcorrido. (MONTELLO, 1986, p. 56, grifo nosso).

Assim, um eventual tom político que o leitor possa recolher da obra romanesca em questão deve estar em consonância com os objetivos do autor. Dessa maneira, a questão de influência, apesar de ser patente e provável, nunca poderá ser classificada como intencional, afinal, não existem dados para que tal sentença seja afirmada ou negada. Mesmo que Montello tenha recolhido essa influência com algum grau de ciência de que já tinha lido aquilo que escrevia, ainda assim, a questão estaria aberta. Larbaud (apud SAMOYAULT, 2008, p. 134) resume essa discussão da seguinte maneira:

“De onde você pegou isso?', 'De onde ele pegou isso?" Eis a questão que sempre tive vontade de me colocar quando ouço ou leio uma obra literária digna desse nome [...]. E 'de onde peguei isso?' é uma pergunta que faço também a mim mesmo cada vez, - isto é, muito raramente, que não sei de onde "pego isso". (LARBAUD apud SAMOYAULT, 2008, p. 134)

\footnotetext{
5 "- Se seus personagens não falarem de política - continua o editor -, não serão mais franceses de 1830, e o seu livro não será mais um espelho, de acordo com suas pretensões..." (STENDHAL, 2016, p. 398, tradução livre).
} 
Quer seja na memória de Julien, quer seja no tom político atribuído à obra, parece claro que a presença de O vermelho e o negro, na biblioteca montelliana abre um caminho de influência na criação do autor maranhense. Como se isso ainda não bastasse, ainda temos o fato de que uma dessas edições está recheada da marginália que aponta para esse caminho, tornando crível o apontamento de que $O$ vermelho e o negro esteve presente nos momentos de gestação de Os tambores de São Luís.

\section{Considerações finais}

A título de encerramento desta empreitada, algumas reflexões são postas para apreciação. Uma delas diz respeito ao valor que ainda pode ter o ineditismo no nosso sistema literário. Esperamos que as discussões propostas aqui tenham demonstrado que a circulação de ideias na literatura é algo comum, técnica da qual se serviram grandes escritores. Longe de significar falta de ideias ou mesmo plágio, esse tomarpara-si constitui-se como técnica de criação literária. Vale lembrar que o simples fato de se servir de uma ideia de outrem não inviabiliza a qualidade da obra. Pelo contrário, estudar como ideias semelhantes servem a propósitos diferentes em sistemas literários diferentes é um caminho que se abre para pesquisas futuras. Esperamos que esse trabalho possa ser desenvolvido nesse ponto, quer seja a título de complementação ou de confrontação.

Uma outra reflexão que pode ser feita a partir das discussões levantadas aqui diz respeito ao próprio fazer literário montelliano. Considerado como um dos romancistas que mais souberam traduzir o Maranhão em suas obras literárias, esperamos contemplar uma outra via de pesquisa com a concretização desta. Essa outra via se constitui como um estudo das afiliações montellianas. Renegando a tradição regionalista em voga durante seu início de carreira literária, Josué Montello empreende um esforço para se aproximar de seus mestres, principalmente no que diz respeito ao gênero romanesco. É por isso que no período compreendido entre 1952 e 1959, o autor deixa de lançar romances. A décima noite, publicado em 1959, começa a ser escrito em 1957 - como vimos num excerto de seu diário reproduzido na seção 2 deste trabalho - o que demonstra que, durante cinco anos - talvez o maior tempo "estéril" de toda a sua carreira - Montello se preocupa em dar forma e conteúdo aos seus romances compatíveis com a sua ideia de literatura, recolhida justamente daqueles que ele admirava, entre os quais está Stendhal. 
Por fim, resta a consciência de que nenhuma pesquisa é uma rocha, livre de consequências das ações do ambiente a sua volta. Certo de, mesmo com a vontade de completude, ter deixado lacunas impostas pelas vicissitudes do labor inerente à pesquisa, esperamos que outros venham preenchê-las.

\section{Referências}

LOPEZ, Telê Ancona. A criação literária na biblioteca do escritor. Cienc. Cult., São Paulo, v. 59, n. 1, p. 33-37, Mar. 2007 . Disponível em: $<$ http://cienciaecultura.bvs.br/scielo.php?script=sci_arttext\&pid=S000967252007000100016\&lng=en\&nrm=iso>. Acesso em: 10 out. 2020.

MONTELLO, Josué. Antes do romance. In: Cais da Sagração. 9. ed. São Luís: Edições Academia Maranhense de Letras, 2017.

. Confissões de um romancista. In: Romances e novelas. Rio de Janeiro: Nova Aguilar, 1986. Vol. 1. p. 13-72.

. Conversa para leitores de Stendhal. In: Areia do tempo: crônicas sobre a cultura francesa e seus autores. São Luís: Edições SECMA; Casa de Cultura Josué Montello, 2009. p. 303-305.

. Diário da manhã. In: Diário completo. Rio de Janeiro: Nova Aguilar, 1998. Vol. 1. p. 21-474. . História deste livro. In: Os tambores de São Luís. 1. ed. especial. vol. 2. São Luís: Edições SECMA/CCJMA, 2019. p. 732-735. . Os tambores de São Luís. 1. ed. especial. São Luís: Edições SECMA/CCJMA, 2019.

. O vermelho e o negro, de Stendhal. Manchete, Rio de Janeiro, n. 1124, 3 nov. 1973. p. 101-104. Disponível em: memoria.bn.br/DocReader/DocReader.aspx?bib=004120\&pagfis=137325. Acesso em: 10 out. 2020.

MOISÉS, Massaud. A literatura portuguesa. 37. ed. São Paulo: Cultrix, 2013.

NERES, José. A história como cenário da arquitetura romanesca da literatura maranhense. In: NERES, José. Na trilha das palavras: estudos literários. São Luís: Café e Lápis; Edições AML, 2015.

OLIVEIRA, Franklin de. A saga romanesca de Josué Montello. Rio de Janeiro: Contra Capa, 2017.

SOUSA, Meridalva Gonçalves de. O negro em Montello: uma análise da personagem Damião em Os tambores de São Luís. In: SANTOS, Silvana Maria 
Pantoja dos; CAVALCANTE, José Dino; SOUZA, Joseane Maria de Souza e. (orgs.). Josué Montello: entre memória, ficção e cultura. São Luís: EDUFMA, 2018.

SAMOYAULT, Tiphaine. A intertextualidade. São Paulo: Aderaldo \& Rothschild, 2008.

STENDHAL. O vermelho e o negro. Trad. Raquel Prado. Porto Alegre: Dublinense, 2016.

STENDHAL. Le rouge et le noir. Paris: Librairie Garnier Frères, 1939. 